\title{
Differential maternal allocation following mixed insemination contributes to variation in oocyte size in a sea squirt
}

\author{
Katrin Hammerschmidtt ${ }^{1,2,3, *}$, Andrew J. Pemberton ${ }^{1}$, Nico K. Michiels ${ }^{2,4}$, \\ John D. D. Bishop ${ }^{1}$ \\ ${ }^{1}$ Marine Biological Association, Citadel Hill Laboratory, Plymouth, PL1 2PB, UK \\ ${ }^{2}$ Institute for Animal Evolution and Ecology, University Münster, 48149 Münster, Germany \\ ${ }^{3}$ Present address: NZ Institute for Advanced Study, Massey University, Auckland, New Zealand \\ ${ }^{4}$ Present address: Faculty of Science, Department of Biology, University of Tübingen, 72076 Tübingen, Germany
}

\begin{abstract}
In many organisms, offspring fitness is markedly affected by size at hatching. Theoretical models predict offspring from one clutch to have the same optimal size, but empirical studies report within-clutch variation in offspring sizes for a wide range of species. According to the differential allocation hypothesis, this could be explained, at least in part, by multiply mated females selectively provisioning their offspring depending on the sperm donor. We tested this hypothesis in the internally fertilising, colonial sea squirt Diplosoma listerianum, whose larvae are non-feeding so that females' provisioning of oocytes provides all of the energy for larval dispersal and metamorphosis. We show that there is high within-clutch variation in offspring size in a natural $D$. listerianum population. When we then crossed laboratory clones pairwise in a fully factorial design in the laboratory, we found that the same acting female clone produced differently sized oocytes with different mating partners. This result does not reflect the effect of direct male benefits, as the water-borne sperm cell is the only contact between males and females, but nevertheless indicates that females allocate resources to their offspring in part influenced by the father's identity. This pattern would be expected to contribute to within-clutch variation in offspring size in mixed-paternity broods.
\end{abstract}

KEY WORDS: Differential allocation - Oocyte size · Offspring fitness · Maternal investment . Diplosoma listerianum

\section{INTRODUCTION}

For all organisms, offspring size is crucial for survival and performance later in life (Stearns 1992). Theory predicts this size to be optimised, in part as a consequence of the trade-off between offspring size and number (Roff 1992). Despite the importance of offspring size for both mothers and progeny, empirical studies have shown high variation in offspring size, even within individual clutches (McEdward \& Coulter 1987, Marshall \& Keough 2007). Whereas variation between species and among populations can mostly be attributed to variation in natural selection (Fox \& Czesak 2000), variation within clutches is more difficult to ex- plain (see Marshall et al. 2008 for review). Apart from physiological limitations that can generate noise in offspring size (Roff 1992, Fox \& Czesak 2000), bet hedging under fluctuating environmental conditions has been suggested as an adaptive explanation (Fox \& Czesak 2000, Crean \& Marshall 2009; for a formal model see Marshall et al. 2008). Here we address another functional explanation for within-clutch variation between offspring: according to the differential allocation hypothesis (Burley 1986, Sheldon 2000), multiply-mated females should allocate resources to offspring depending on the characteristics of their fathers.

We tested this hypothesis in a marine colonial invertebrate, the hermaphroditic ascidian Diplosoma listeri- 
anum. Here, selection pressure on offspring size is high, as larvae are non-feeding, so that all energy for swimming and metamorphosis needs to be provided by the mother. Bigger larvae are associated with higher initial survival and growth rate, and are able to delay settlement for longer periods of time, resulting in settling in higher quality habitats and an increased dispersal potential in the field (Marshall \& Keough 2003, Marshall \& Keough 2005). Nevertheless, a substantial amount of within-population variation in oocyte size has been reported (Marshall \& Keough 2007; see also Allen et al. 2008 for offspring size plasticity in the bryozoan Bugula neritina).

Mixed paternity is common in this and similar species because sperm disperse in water and are subsequently collected individually during filter-feeding (Bishop \& Pemberton 1997, Johnson \& Yund 2007). In Diplosoma listerianum, oocytes are provisioned with yolk only upon receipt of compatible allosperm (Bishop et al. 2000), but the level of investment does not reflect the amount of sperm captured (Bishop 1996). After all maternal investment is complete, ovulation is accompanied by fertilisation using sperm that may have been stored within the ovary for several weeks (Burighel \& Martinucci 1994b). At that time, maternal nutritional investment is terminated and can be assessed in situ because of the transparent and thin colonial tunic. After fertilisation, eggs are released into the basal tunic of the colony, where embryos develop independently until the mature larvae leave the colony (Brunetti et al. 1988). This 'free-spawning egg brooder' = 'spermcast' pattern is common among sessile species. The triggering of egg growth by received sperm has been described in the bryozoan Celleporella hyalina (Bishop et al. 2000), and is likely to occur in many other gymnolaemate bryozoans. In many sponges, sperm are taken in and sit adjacent to growing oocytes, suggesting a similar arrangement (for more details see Bishop \& Pemberton 2006).

To investigate whether mothers do provision offspring within one egg cohort differently, we assessed variation in oocyte size in colonies collected from a natural population of Diplosoma listerianum. We further linked oocyte size to larval size, as bigger oocytes cannot be assumed to develop into bigger larvae. In controlled matings in the laboratory with a different set of clones, we then tested whether variation in offspring size could be caused by differential provisioning following receipt of sperm from different sources.

\section{MATERIALS AND METHODS}

Natural variation in egg and larval size. Wild colonies of Diplosoma listerianum were collected in Queen Anne's Battery Marina in Plymouth, UK. Each of the 7 colonies was checked for colour uniformity to minimise the probability of chimerism (Sommerfeldt et al. 2003), and kept in the laboratory for $2 \mathrm{~d}$. Hatched clear-tailed larvae (a fully developed, well-defined swimming stage) were collected and a digital image taken immediately with a KY-F50 JVC colour video camera mounted on a Wild dissecting microscope. After pictures from 15 larvae per colony had been obtained, pictures of 15 oocytes were taken.

Oocytes were only photographed when they had a conspicuous cap-like layer of white granulocytes on the opposite side to that of the egg-ovary attachment. This is the oocyte stage in Diplosoma listerianum when female investment is completed and oocytes are about to be ovulated but are not fertilised yet (Martinucci et al. 1988). All image files were coded and randomised to avoid observer bias and processed with the Zeiss KS 300.3 image analysis system. To facilitate comparison to other studies on offspring size in marine invertebrates, we chose to measure oocyte diameter, which is the parameter most commonly used in this field (see Marshall \& Keough 2007 for more details), rather than oocyte volume. The diameter of each oocyte was determined using the image analysis system by fitting a circle around the circumference of the egg. For larval size, trunk length was determined by drawing a vector from the outer edge of the middle adhesive papilla to the meeting point of tail and trunk.

Effect of male identity on egg size. Colonies of Diplosoma listerianum can be reared in reproductive isolation in the laboratory as they are self-incompatible, and fail to produce eggs when reared in reproductive isolation, despite prolonged exposure to self sperm (Bishop 1996). By cutting colonies into pieces and reattaching them to separate glass slides, genotypes can be replicated as virgin sub-colonies (ramets; Bishop et al. 2001). Here, virgin ramets of 8 established genetically different laboratory clones were grown in the same culture room but in reproductive isolation from each other prior to the start of the experiment. All clones were different from the ones collected in the field; they were specifically chosen from the laboratory stock population for their high level of compatibility in the intended crosses (information from preliminary crosses). This was done to ensure enough progeny for analysis. Immediately before the experiment, all ramets were cut down to $55 \pm 5$ zooids. Colonies that had the right number of zooids were also cut, but without removing zooids. Only sexually mature ramets with sperm visible in the seminal vesicles were used.

Four clones designated as acting females (A, B, C, D; referred to below as female clones) were crossed with 4 others (clones 1, 2, 3,4) designated as acting males (referred to below as male clones). To accomplish this, 2 mature but virgin ramets were placed in the same 
culture tank ( $800 \mathrm{ml}$ water). We used a fully factorial design (16 combinations, each replicated twice). To saturate the female reproductive tract with sperm, the 2 colonies were kept in the same tank for $1 \mathrm{wk}$, after which the male ramet was discarded and the water in the tank was changed.

All crosses were done simultaneously. Food, water level and salinity were similar for all tanks (Bishop et al. 2001). The tanks with the female clones were placed in random order on the shelves of the culture room and redistributed every $3 \mathrm{~d}$ to minimise the possibility of variation in egg size due to tank position. Starting $9 \mathrm{~d}$ after mating until either egg production stopped or more than 30 oocytes had been measured, female ramets were checked once every 3rd day for mature oocytes at the stage just before ovulation (i.e. possessing the granulocyte cap: see above for more information). Preliminary observations showed that the longest time oocytes stayed in the granulocyte-cap phase prior to ovulation was $48 \mathrm{~h}$, so the same oocyte would not have been measured twice. All measurements were made blind to the treatment.

Statistical analyses. Wild colonies: Variation in oocyte and larval sizes was assessed using 1-way analyses of variance (ANOVAs) with colony as the effect variable. We tested whether egg size influenced larval size, using colony means for both variables, with a Pearson correlation. Coefficients of variation (CVs) were calculated as a measure of variation.

Laboratory crosses: To check for female and male effects and for interactions between them, a 2-way crossed ANOVA with oocyte diameter as the dependent variable and the 2 fixed factors male and female was carried out. The factors cannot be treated as random, as only highly compatible male $\times$ female combinations were selected from the laboratory stock, so they are representative of a subset of the population only (Quinn \& Keough 2003). The unit of analysis was the female ramet $(n=32)$, i.e. all measurements of oocyte diameter were averaged for each ramet, before the 2-way ANOVA was carried out. To test for a trade-off between oocyte size and number, i.e. the production of many but smaller oocytes with certain males, we used data on total oocytes produced from a study that used the same female-male combinations under the same culture conditions (unpublished data). We related oocyte size to oocyte number with a Pearson correlation. CVs were calculated as a measure of oocyte variation for each female clone (mated to the 4 different males), and for all oocytes measured in this experiment.

Normal distribution and equal variances were confirmed with the Shapiro-Wilk test and Levene's test. Effects were considered significant at $p<0.05$. All test statistics are 2-tailed and were performed in JMP 5.0.1.2 for Macintosh.

\section{RESULTS}

\section{Natural variation in oocyte and larval size}

The level of within-population variability of oocyte size (CV of oocyte diameter) in the wild Diplosoma listerianum population was $8.28 \%$ (Fig. 1). Oocyte and larval sizes varied significantly depending on their colony of origin (oocytes: $\mathrm{R}^{2}=0.55, F_{6,98}=20.016, \mathrm{p}<$ 0.0001 ; larvae: $\mathrm{R}^{2}=0.21, F_{6,98}=4.475, \mathrm{p}=0.0005$ ), indicating strong maternal, genetic and/or environmental effects. Within individual colonies, the $\mathrm{CV}$ of oocyte diameter ranged from 4.18 to $6.44 \%$, and the CV of larval size from 4.86 to $7.67 \%$. Oocyte size and larval size were positively correlated (Pearson $\mathrm{r}=0.828, \mathrm{n}=7, \mathrm{p}=$ 0.021; Fig. 2).

\section{Effect of male identity on oocyte size}

After the 32 female $\times$ male crosses had been performed, 863 oocytes were measured (Fig. 3). Oocyte size in the pairwise matings was significantly explained by the 2-way crossed ANOVA, with female and male clones $\left(\mathrm{R}^{2}=0.72, F_{15,16}=2.732, \mathrm{p}=0.0272\right)$. Effect tests revealed significant female $\left(F_{3}=7.680, \mathrm{p}=\right.$ $0.0021)$ and male $\left(F_{3}=4.1866, \mathrm{p}=0.0229\right)$ effects, but a non-significant interaction effect $\left(F_{9}=0.5979, \mathrm{p}=\right.$ $0.7810)$.

There was no trade off between oocyte size and number across all female $\times$ male clone combinations, but a trend towards a positive relationship was observed (Pearson $r=0.480, \mathrm{n}=16, \mathrm{p}=0.0598$; Fig. 4).

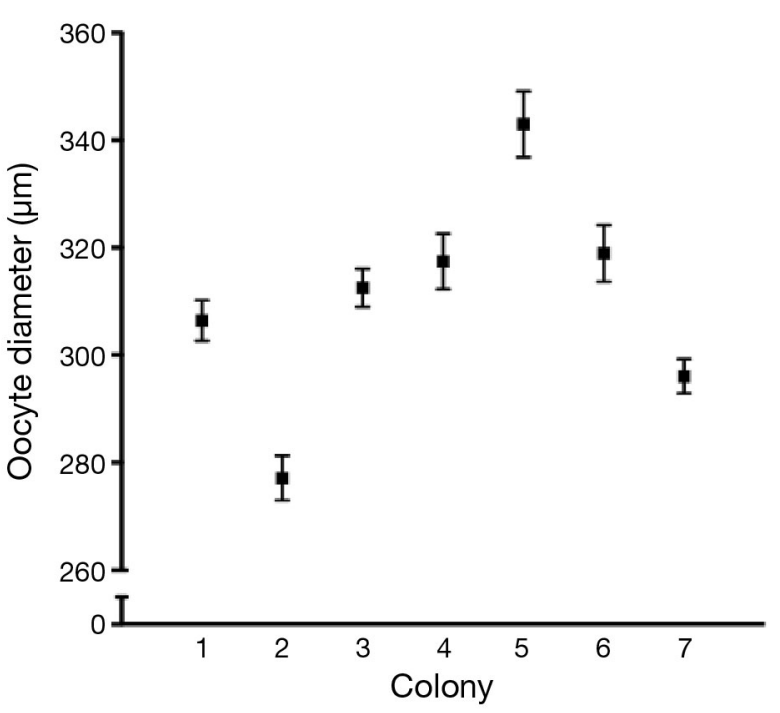

Fig. 1. Diplosoma listerianum. Variation in oocyte diameter between and within wild colonies (mean $\pm \mathrm{SE} ; \mathrm{n}=105)$ 


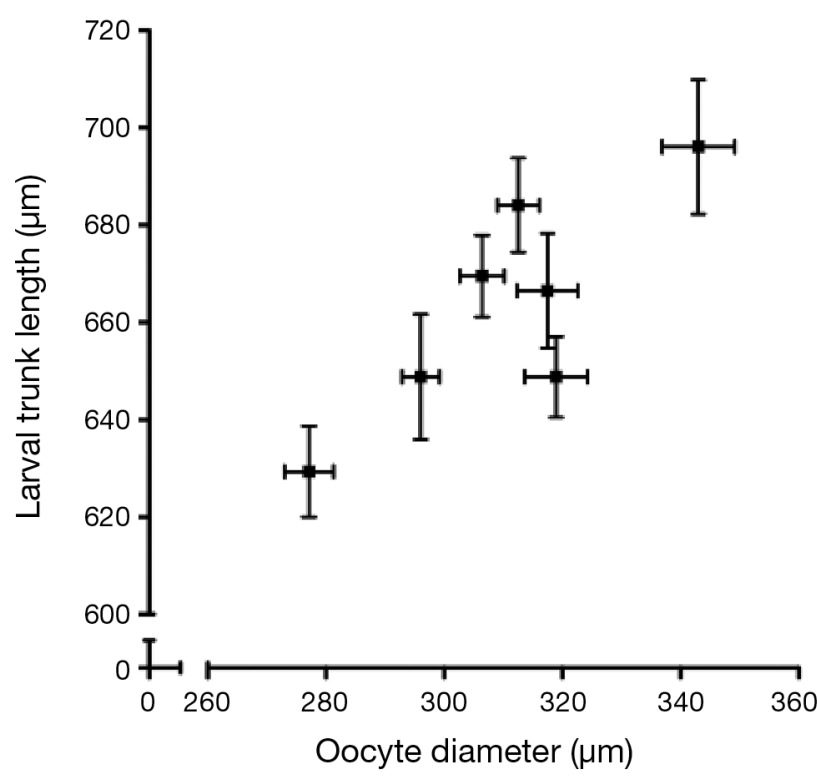

Fig. 2. Diplosoma listerianum. Relationship between oocyte diameter and larval size in wild colonies (mean $\left.\pm \mathrm{SE}_{;} \mathrm{n}=105\right)$

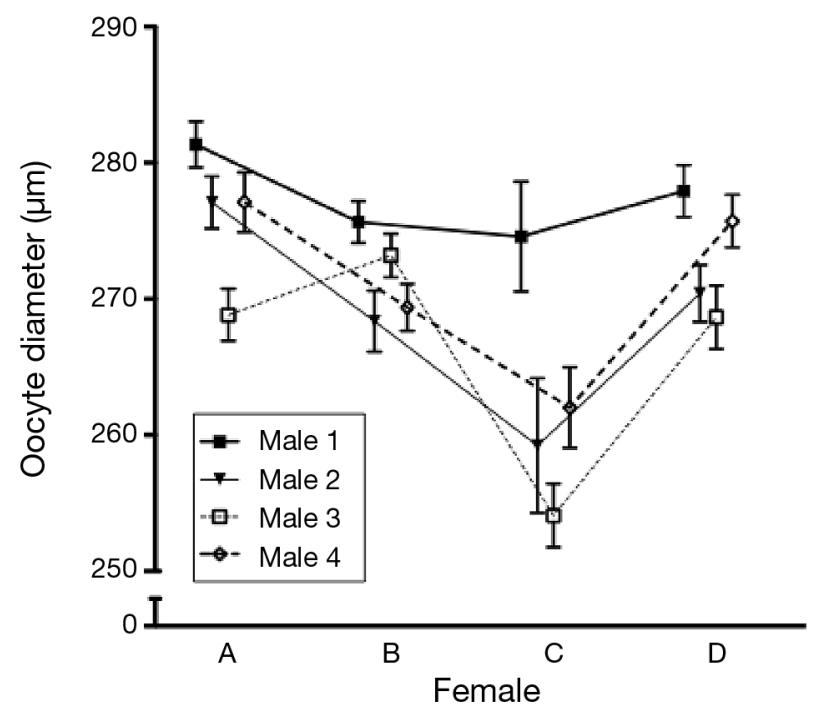

Fig. 3. Diplosoma listerianum. Variation in oocyte diameter in laboratory colonies (mean $\pm \mathrm{SE}_{;} \mathrm{n}=863$ ) produced by 4 female clones following separate matings to 4 male clones

CVs of the oocytes from each female clone combined across all 4 crosses in which that clone was involved ranged from 5.22 to $8.00 \%$, with a mean of $6.31 \%$.

Oocytes from laboratory crosses were smaller than those from wild colonies. This can be explained by the different environmental conditions between the laboratory and the field. Nevertheless, as all ramets in this experiment were treated identically, the effects described remain valid even if the conditions were obviously different from those in the field.

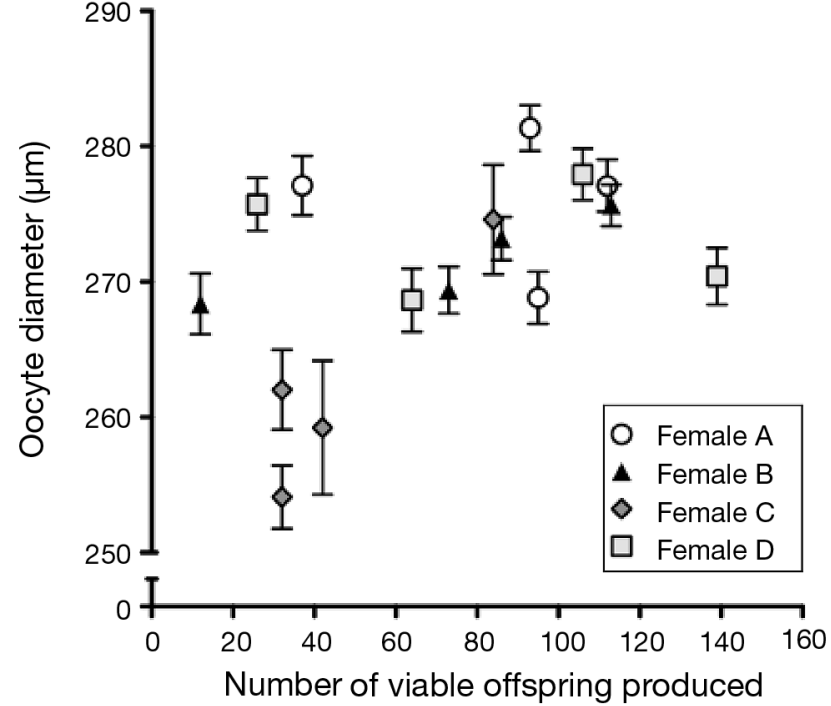

Fig. 4. Diplosoma listerianum. Relationship between oocyte diameter and number of viable offspring in the female-male laboratory crosses

\section{DISCUSSION}

In marine invertebrates, maternal investment is a major factor in shaping population structure and dynamics in nature (Marshall \& Keough 2007). Despite its importance, mothers have been found to differentially provision offspring within the same clutch. We here provide an explanation for the variation in progeny size within clutches of a colonial marine invertebrate with nonfeeding larvae: mixed paternity could contribute to within-brood size variation in the internally fertilising colonial ascidian Diplosoma listerianum. This species provisions eggs after the receipt of sperm, but before fertilisation. When mated under controlled conditions in the laboratory, female clones produced differently sized oocytes with different sperm donors. In a natural population, in which mixed insemination would be expected, offspring size (both oocytes and larvae) varied extensively within as well as between colonies. The overall variation in oocyte size within single wild colonies (CV: $4.18-6.44 \%$ ) and the similar overall CVs in this UK population ( $8.28 \%$ ) and in an Australian one $(9.32 \%$, Marshall \& Keough 2007) suggest that differential oocyte provisioning might be ubiquitous in this species. Oocyte size variation in laboratory crosses was smaller overall (CV: $6.31 \%$, calculated for all oocytes measured is this experiment), which might, at least in part, reflect more uniform environmental conditions. Nevertheless, the CVs for individual female clones for oocytes pooled across laboratory matings to 4 different males $(5.22,5.54,5.68,8.00 \%)$ were comparable to those for colonies in the wild (4.18-6.44\%). 
For differential maternal allocation to contribute to variance in progeny size within natural broods as suggested, the provisioning of individual oocytes during vitellogenesis would have to be influenced by the identity of a particular sperm source, even following mixed insemination. The anatomy of the ovary and pattern of sperm storage within it suggest that it is indeed entirely possible that the development of an oocyte is influenced by individual sperm. The ovary of Diplosoma listerianum is branched, and the stored sperm are distributed among narrow blind-ended diverticula that each penetrate the follicle cell layers of an immature oocyte and terminate in contact with its vitelline coat (Burighel \& Martinucci 1994a,b, Bishop \& Sommerfeldt 1996), with the furthest advanced sperm in each diverticulum thus in extreme proximity to the developing oocyte during vitellogenesis.

As female investment in progeny occurs after sperm receipt but before fertilisation, it is possible to discount the possibility that male genetic material directly contributes to oocyte size before oocyte investment is complete. The occurrence of differential provisioning reflecting male identity in Diplosoma listerianum appears remarkable given that the sperm cell is the only contact between acting males and the acting female in this remotely mating, sessile species, in which paternal care or other possible direct benefits can be excluded. Given that males do not provide any resources or protection, we are able to exclude the possibility that direct benefits from the male influence oocyte size. Although extreme care is needed in ascribing differential maternal allocation into progeny of different males to genetic (indirect) benefits (Colegrave 2001, Cunningham \& Russell 2000), our results nevertheless document differential maternal investment in progeny in the undoubted absence of direct benefits. Other studies that have supported the differential allocation hypothesis could not fully exclude selection operating through direct benefits (Gil et al. 1999, Cunningham \& Russell 2000, Kolm 2001). There are indications in other species that differential allocation is positively genetically linked to male quality (Head et al. 2006, Harris \& Uller 2009) and/or attractiveness (Gilbert et al. 2006, Bonato et al. 2009, Evans et al. 2010), which would provide an adaptive explanation for the resulting within-clutch variation in oocyte size. An alternative possibility, involving sexual conflict, is that sperm differs, according to its source, in its ability to manipulate the recipient colony to increase maternal investment. This might conceivably involve haploid gene expression in stored sperm (Immler 2008), a possibility further hinted at by the metamorphosis undergone by sperm of $D$. listerianum upon entry into the recipient ovary (Burighel \& Martinucci 1994a).
Acknowledgements. We thank C. Wood and D. Sommerfeldt for help during the experiment, J. Rolff for help with the statistics and K. Reinhardt and 3 anonymous referees for comments on the manuscript. K.H. was funded by the Heinrich Hertz Stiftung, Düsseldorf.

\section{LITERATURE CITED}

Allen RM, Buckley YM, Marshall DJ (2008) Offspring size plasticity in response to intraspecific competition: an adaptive maternal effect across life-history stages. Am Nat 171:225-237

> Bishop JDD (1996) Female control of paternity in the internally fertilizing compound ascidian Diplosoma listerianum. I. Autoradiographic investigation of sperm movements in the female reproductive tract. Proc Biol Sci 263: 369-376

Bishop JDD, Pemberton AJ (1997) Sessile animals: attached, but promiscuous? Trends Ecol Evol 12:403

- Bishop JDD, Pemberton AJ (2006) The third way: spermcast mating in sessile marine invertebrates. Integr Comp Biol 46:398-406

Bishop JDD, Sommerfeldt AD (1996) Autoradiographic investigation of uptake and storage of exogenous sperm by the ovary of the compound ascidian Diplosoma listerianum. Mar Biol 125:663-670

Bishop JDD, Manríquez PH, Hughes RN (2000) Water-borne sperm trigger vitellogenic egg growth in two sessile marine invertebrates. Proc Biol Sci 267:1165-1169

Bishop JDD, Pemberton AJ, Sommerfeldt AD, Wood CA (2001) Laboratory studies of mating in the aplousobranch Diplosoma listerianum. In: Sawada H, Yokosawa H, Lambert CC (eds) The biology of ascidians. Springer Verlag, Tokyo, p 305-310

> Bonato M, Evans MR, Cherry MI, Michael I (2009) Investment in eggs is influenced by male coloration in the ostrich Struthio camelus. Anim Behav 77:1027-1032

Brunetti R, Bressan M, Marin M, Libralato M (1988) On the ecology and biology of Diplosoma listerianum (Milne Edwards, 1841) (Ascidiacea, Didemnidae). Vie Milieu 38: 123-131

Burighel P, Martinucci GB (1994a) Sexual reproduction in the compound ascidian Diplosoma listerianum (Tunicata). I. Metamorphosis, storage and phagocytosis of sperm in the female duct. Mar Biol 118:489-498

Burighel P, Martinucci GB (1994b) Sexual reproduction in the compound ascidian Diplosoma listerianum (Tunicata). II. Sperm penetration through ovary wall and evidence of internal fertilization. Mar Biol 118:499-510

Burley N (1986) Sexual selection for aesthetic traits in species with biparental care. Am Nat 127:415-445

Colegrave N (2001) Differential allocation and 'good genes' comment from Colegrave. Trends Ecol Evol 16:22-23

Crean AJ, Marshall DJ (2009) Coping with environmental uncertainty: dynamic bet hedging as a maternal effect. Philos Trans R Soc Lond B Biol Sci 364:1087-1096

Cunningham EJA, Russell AF (2000) Egg investment is influenced by male attractiveness in the mallard. Nature 404 : $74-77$

> Evans JP, Box TM, Brooshooft P, Tatler JR, Fitzpatrick JL (2010) Females increase egg deposition in favor of large males in the rainbowfish, Melanotaenia australis. Behav Ecol 21:465-469

- Fox CW, Czesak ME (2000) Evolutionary ecology of progeny size in arthropods. Annu Rev Entomol 45:341-369

Gil D, Graves J, Hazon N, Wells A (1999) Male attractiveness 
and differential testosterone investment in zebra finch eggs. Science 286:126-128

Gilbert L, Williamson KA, Hazon N, Graves JA (2006) Maternal effects due to male attractiveness affect offspring development in the zebra fish. Proc Biol Sci 273:1765-1771

Harris WE, Uller T (2009) Reproductive investment when mate quality varies: differential allocation versus reproductive compensation. Philos Trans R Soc Lond B Biol Sci 364:1039-1048

Head ML, Hunt J, Brooks R (2006) Genetic association between male attractiveness and female differential allocation. Biol Lett 2:341-344

Immler S (2008) Sperm competition and sperm cooperation: the potential role of diploid and haploid expression. Reproduction 135:275-283

Johnson SL, Yund PO (2007) Variation in multiple paternity in natural populations of a free-spawning marine invertebrate. Mol Ecol 16:3253-3262

Kolm N (2001) Females produce larger eggs for larger males in a paternal mouthbrooding fish. Proc Biol Sci 268: 2229-2234

Marshall DJ, Keough MJ (2003) Variation in the dispersal potential of non-feeding invertebrate larvae: the desperate larva hypothesis and larval size. Mar Ecol Prog Ser 255:145-153

Marshall DJ, Keough MJ (2005) Offspring size effects in the marine environment: a field test for a colonial inverte-

Editorial responsibility: Roger Hughes,

Bangor, UK brate. Austral Ecol 30:275-280

> Marshall DJ, Keough MJ (2007) The evolutionary ecology of offspring size in marine invertebrates. Adv Mar Biol 53: $1-60$

Marshall DJ, Bonduriansky R, Bussière LF (2008) Offspring size variation within broods as a bet-hedging strategy in unpredictable environments. Ecology 89:2506-2517

Martinucci GB, Burighel P, Zaniolo G, Brunetti R (1988) Ovulation and egg segregation in the tunic of a colonial ascidian, Diplosoma listerianum (Tunicata, Ascidiacea). Zoomorphology 108:219-227

McEdward LR, Coulter LK (1987) Egg volume and energetic content are not correlated among sibling offspring of starfish: implications for life-history theory. Evolution 41: 914-917

Quinn GP, Keough MJ (2003) Experimental design and data analysis for biologists. Cambridge University Press, Cambridge

Roff DA (1992) The evolution of life histories. Theory and analysis. Chapman \& Hall, New York, NY

Sheldon BC (2000) Differential allocation: tests, mechanisms and implications. Trends Ecol Evol 15:397-402

Sommerfeldt AD, Bishop JDD, Wood CA (2003) Chimerism following fusion in a clonal ascidian (Urochordata). Biol J Linn Soc 79:183-192

Stearns SC (1992) The evolution of life histories. Oxford University Press, Oxford

Submitted: June 23, 2010; Accepted: October 21, 2010

Proofs received from author(s): January 13, 2011 